\title{
REFLEXIONES EN TORNO AL CONTROL DE CONSTITUCIONALIDAD DEL DERECHO COMUNITARIO
}

JASONE ASTOLA MADARIAGA

Profesora Titular de Teoría del Estado y Derecho Constitucional Universidad del País Vasco / EHU 


\section{SUMARIO}

I. INTRODUCCIÓN: LA CONSTITUCIONALIDAD DE LOS TRATAdOS COMUNITARIOS. II. ALgunAS PUNTUALIZACIONES SOBRE EL CONCEPTO DE CONSTITUCIÓN EUROPEA. III. LOS MECANISMOS TRADICIONALES DE CONTROL CONSTITUCIONAL EN EL SISTEMA COMUNITARIO. IV. LA IMPORTANCIA SOBREVENIDA DEL TRIBUNAL DE JUSTICIA EN EL SISTEMA COMUNITARIO. 1. El posible control de constitucionalidad sobre el derecho derivado comunitario y sobre la jurisprudencia del TJ. 1.1. Las dificultades de la vertebración jurídica de un mecanismo compartido de control. V. RECAPITULACIÓN. 


\title{
REFLEXIONES EN TORNO AL CONTROL DE CONSTITUCIONALIDAD DEL DERECHO COMUNITARIO*
}

POR

\author{
JASONE ASTOLA MADARIAGA \\ Profesora titular de Teoría del Estado y Derecho Constitucional \\ Universidad del País Vasco / EHU
}

\section{INTRODUCCIÓN: LA CONSTITUCIONALIDAD DE LOSTRATADOS COMUNITARIOS}

La segunda mitad del siglo XX puede caracterizarse, en Europa, como la época de la apertura constitucional a los sistemas internacionales. Este proceso comenzó al acabar la segunda guerra mundial y perseguía el objetivo de conseguir una paz duradera en el continente. Las Comunidades Europeas y el Consejo de Europa (la firma de la CEDH $)^{1}$ son dos claros ejemplos de esta apertura constitucional ${ }^{2}$.

* Este trabajo es una parte del proyecto de investigación subvencionado por el Ministerio de Educación y Cultura, Plan Nacional de I+D, PB 98-0155 con el título «El control de validez de las normas en los sistemas juridicos occidentales: especial referencia al control de constitucionalidad", dirigido por el profesor Eduardo VIRGala ForURIA.

1 Esta apertura constitucional es tratada por KIRCHHOF, Paul, «Verfassungsrechtlicher Schutz und Internationaler Schutz der Menschenrechte: Konkurrenz oder Ergänzung? -Landesbericht Deutschland-n, Europäische Grundrechte-Zeitschrift, 1994, pág. 16.

2 Esta actitud de los Estados europeos de buscar soluciones comunes a sus problemas fue pronto puesta en evidencia por la doctrina, citaremos como ejem- 
Este proceso ha presentado numerosos problemas jurídicos $y$, entre éstos, los últimos y más significativos han sido, sin duda, los planteados en torno a la ratificación del Tratado de Maastricht, cuya constitucionalidad se puso en duda en varios países miembros de la Comunidad ${ }^{3}$.

Las discusiones abiertas en torno a esta ratificación nos permiten señalar que el Derecho Constitucional no ha perdido su carácter de orden central (básico, eje) para la política del Estado en todas sus manifestaciones, internas, internacionales o comunitarias ${ }^{4}$.

Por eso resulta extraño, por redundante, que el Tratado de Amsterdam, en el art. 6.3 del TUE ("La Unión respetará la identidad nacional de sus Estados miembros"), recoja la protección de las identidades nacionales, ya que la Unión europea no es más, ni menos, que el desarrollo reciente que han tenido los órdenes constitucionales de los Estados, cuya identidad, hasta el momento, nunca se ha puesto en duda 5 .

plo a RIVERo, Jean, "Vers un droit commun européen en droit administratif», en CAPELLETT, Mauro (ed.), New perspectives for a common law of Europe, Leyden Sijthoff 1978, pág. 389.

3 La ratificación de este Tratado fue discutida por los órganos encargados del control de constitucionalidad en: Alemania (Sentencia de 12 de octubre de 1993, BverfGE 89, pág. 155); España (dictamen del TC de 1 de julio de 1992); Francia (3 dictámenes del Consejo Constitucional, Maastricht I $-\mathrm{N} \cdot{ }^{\circ} 92-308$, de 9 de abril de 1992-, Maastricht II $-\mathrm{N} .^{\circ}$ 92-312, de 2 de septiembre de $1992-$ y Maastricht III $-N .^{\circ}$ 92-313, de 23 de septiembre de 1992-); Dinamarca (Sentencia delTS de 6 de abril de 1998 -N. ${ }^{\circ}$ I 361/1997 -), y Reino Unido (TS de Londres, ex parte Lord Rees Mogg, sentencia de 30 de julio de 1993). Un estudio general de algunas de estas sentencias puede verse en WEBER, Albrecht, "El control del Tratado de Maastricht por la jurisdicción constitucional desde una perspectiva comparadan, Revista Española de Derecho Constitucional, n. ${ }^{\circ} 45,1995$, págs. 31-51.

4 EITS danés (sentencia de 6 de abril de 1998, asunto I 361/97) ha dicho expresamente que la Comunidad no tiene poder para adoptar normas contrarias a la Constitución danesa; el Budesverfassungsgerich ha dejado claro que la transferencia de competencias a la Comunidad no afecta la base del orden constitucional en Alemania; la Corte Costituzionale italiana considera que el derecho comunitario no puede prevalecer en contra de los principios fundamentales de la Constitución italiana (Frontini, decisión n. ${ }^{\circ} 183$ de 27 de diciembre de 1973, párrafo 21); de la decisión de 9 de abril de 1992 del Conseil Constitutionnel francés y del dictamen de 1 de julio de 1992 sobre elTUE delTC español se desprende también la preeminencia de la Constitución.

5 El punto de vista contrario puede verse en BEUTLER, Beng, «Artikel F als "Verfassungsfragment" ", en GROEBEN, THIESING y EHLERMANN (Hrsg), Kommentar zum EU-/EG-Vertrag, vol. 1, Nomos, Baden-Baden, 1997, págs. 78-133, especialmente 
Pero, haciendo una lectura positiva del art. 6.3 delTUE, podemos decir que cuando la Unión asume el respeto de los sistemas constitucionales, además de estar reconociendo su diversidad (no podemos olvidar las diferencias que existen entre los sistemas constitucionales de los Estados europeos y no únicamente entre el orden anglosajón y el continental/ ${ }^{6}$, está reconociendo el respeto de los principios constitucionales de los Estados miembros (EE.MM. desde ahora) y este respeto se puede entender en dos sentidos: 1) como un límite para las tendencias unificadoras del derecho comunitario7; y 2) como la última base jurídica de la que parte todo el proceso de integración europea ${ }^{8}$.

\section{ALGUNAS PUNTUALIZACIONES SOBRE EL CONCEPTO DE CONSTITUCIÓN EUROPEA}

La base normativa de la Unión Europea (desde ahora UE) es considerada por unos como una "Constitución" " mientras que otros plantean la necesidad de un texto constitucional ${ }^{10}$. Unos y otros encuen-

pág. 133, porque desde la perspectiva de este autor el art. 6 del TUE es, precisamente, la "pequeña Constitución" (Kurzverfassung) de la Unión, porque en él se incluyen sus elementos estructurales: la posición de los Estados, los derechos fundamentales y los medios de los que dispone la Unión.

6 Únicamente por ilustrar con un ejemplo estas diferencias recordemos que en Irlanda el aborto está constitucionalmente prohibido, mientras que en Holanda el derecho al aborto es un derecho individual constitucionalmente garantizado.

7 SCHWARZE, Jürgen, "Die europäische Dimension des Verfassungsrechts", en SCHWARzE, Jürgen (Hrsg.), Verfassungsrecht und Verfassungsgerichtsbarkeit im Zeichen Europas, Nomos Verlagsgesellschaft, Baden-Baden, 1998, págs. 137-167, especialmente págs. 144-164 resume los problemas juridicos que han planteado los órganos constitucionales en Alemania, Francia, Italia, Reino Unido e Irlanda a propósito de esta defensa del sistema constitucional frente a las tendencias unificadoras del TJ.

8 «Resueltos a sentar las bases de una unión cada vez más estrecha entre los pueblos europeos» es la frase con la que comienza el preámbulo del Tratado de la Comunidad Europea.

9 El propio Tribunal de Justicia de la Comunidad ha dado este apelativo a los tratados, sentencia del Partido ecologista "Los Verdes" contra Parlamento Europeo, de 23 de abril de 1986, Asunto 294/83, Rec. 1986, pág. 1339, v.g. Es interesante la recopilación de artículos sobre este tema que hace MAGNETTE, Paul (ed.), La constitution de l'Europe, Éditions de l'Université de Bruxelles, Bruxelles, 2000.

10 En este sentido, ver las declaraciones del Presidente francés en el discurso que dírigió a la nación con motivo de la fiesta nacional del 14 de julio, recogidas, entre otros, por el diario El Pais, sábado 15 de julio, pág. 5, cuyo titular es significativo "El presidente francés cree necesaria una Constitución europea». 
tran argumentos para defender su tesis ${ }^{11}$ y la razón estriba en que el sistema comunitario no ha sido concebido ni según el modelo tradicional de constitución ${ }^{12}$, ni según el modelo tradicional de organización internacional ${ }^{13}$. De la originalidad del sistema surge, en definitiva, el problema de su definición ${ }^{14}$.

Desde nuestro punto de vista, el concepto "constitución" no debe ser entendido en el espacio europeo como se entiende en el espacio del Estado-nación ${ }^{15}$, básicamente, porque el sistema comunitario no es, por el momento, autónomo de los sistemas constitucionales de los EE.MM., en el sentido de que pudiera existir sin estos "constituidos" ordenamientos jurídicos, frutos del poder constituyente de los diferentes pueblos que conforman Europa ${ }^{16}$.

11 Interesante el trabajo de Llopis Carrasco, Ricardo Miguel, Constitución Europea: un concepto prematuro, Tirant Lo Blanch, Valencia, 2000 donde analiza la jurisprudencia del Tribunal de Justicia de las Comunidades Europeas sobre el concepto de "carta constitucional básica", para ver la confrontación de argumentos.

12 Comenzando por la ausencia de un único pueblo europeo con poder constituyente, de ahi que quepan posiciones contrarias a la existencia de la misma, por todas RUIPÉREZ, Javier, La "Constitución Europea" y la teoría del poder constituyente, Biblioteca Nueva, Madrid, 2000.

13 Rodriguez Iglesias, Gil Carlos, "Zur "Verfassung" der Europäischen Gemeinschaft", en SCHWARZE, Jürgen (Hrsg.), Verfassungsrecht und Verfassungsgerichtsbarkeit im Zeichen Europas, Nomos Verlagsgesellschaft, Baden-Baden, 1998, págs. 45-62, pág. 48, señala que la Comunidad, aunque especial, es una organización internacional y más adelante (pág. 56) argumenta tal posición diciendo que, en la crisis que se produjo en la Comunidad con el no del referéndum danés a Maastricht, las salidas se buscaron en el derecho internacional (más exactamente, en el Convenio de Viena de 23 de Mayo de 1969 sobre el derecho de los Tratados). También en la misma línea y por todos Girón LARruceA, José Antonio, La Comunidad Europea como organización internacional, Ed. Centro de Estudios Ramón Areces, SA, Madrid, 1999.

14 Una de las definiciones para estas nuevas relaciones juridicas ha sido la de "metaconstitucionales". Un análisis de este concepto puede verse en WALKER, Neil, "Flexibility within a metaconstitutional frame: Reflections on the future legal authority in Europe", Harvard Jean Monnet Working Paper 12/99. Trabajo que puede conseguirse en la siguiente dirección de Internet: http://www.jeanmonnetprogram.org/papers/99/991201.rtf

15 En este sentido ver HERTEL, Wolfram, Supranationalität als Verfassungsprinzip -Normativität und Legitimation als Elemente des Europäisches Verfassungsrechts, Duncker \& Humblot, Berlin, 1999, págs. 28 y ss.

16 En este sentido se expresa RoLDÁn BARBERo, Javier, "Las bases estatales delTratado de Amsterdam", en FARIÑÁN GILBERT, Juan Manuel (coord.), Reflexiones en torno al Tratado de Amsterdam y el futuro de la Unión Europea, Ed Comares, Granada, 2000, pág. 52: «El poder constituyente proviene de los Estados miembros 
Son, por lo tanto, los principios constitucionales de los EE.MM. los que marcan el nacimiento del ordenamiento jurídico comunitario ${ }^{17}$, pero estos principios adquieren en la Comunidad ciertas peculiaridades, que no pueden ser explicadas, ni interpretadas, únicamente, como un mero desarrollo de los ordenamientos jurídicos estatales, porque, simultáneamente, la Comunidad es algo más que la suma de estos ordenamientos $^{18}$.

Si analizamos la evolución de la Unión, podemos observar que la dirección seguida no ha sido la de excluir, delimitando espacios cada vez más amplios de autonomía plena, a través de, pongamos por caso, una lista cerrada de competencias exclusivas ${ }^{19}$ o de una búsqueda de un nuevo sujeto de soberanía, sino la de incluir. Es decir, la Unión ha buscado una progresiva interpenetración entre ordenamientos. En los casi cincuenta años que han pasado desde la firma del Tratado CECA no se ha creado un nuevo espacio jurídico-político independiente y alejado de los ordenamientos juridico-constitucionales de los Estados miembros ${ }^{20}$, sino que, por el contrario, tales

y sigue reposando en los mismos". O como dice AlAez Corral, Benito: "Soberanía constitucional e integración europea", Fundamentos, 1/1998, Soberanía y Constitución, pág. 555, «... la validez jurídica y la propia eficacia política del proceso de integración europea dependen, en último extremo, del mantenimiento de la soberanía constitucional".

17 La diferencia entre los ordenamientos constitucionales comienza en la propia categoría de principio constitucional; RIEDEL, Eibe, "Der gemeineuropäische Bestand von Verfassungsprinzipien zur Begründung von Hoheitsgewalt -Legitimation und Souveränität-», en MülleR-GRAFF, P.-Ch., y RIEDEL, E. (Hrsg.), Gemeinsames Verfassungsrecht in der Europäischen Union, Nomos Verl., Baden-Baden, 1998, págs. 77-97, especialmente pág. 83 , después de analizar los principios constitucionales de Alemania, Francia y el Reino Unido llega a la conclusión de que ni siquiera el propio concepto "principio constitucional" significa lo mismo en los tres ordenamientos.

18 Ya que desde el respeto a la diferencia constitucional (que resaltábamos en el anterior pie de pág. I se ha conformado un espacio común con su propia lógica. En este sentido ver BIEBER, Roland, "Verfassungsentwicklung der Europäischen Union: Autonomie oder Konsequenz staatlicher Verfassungsentwicklung?", en Müller-Graff, P.-Ch., y RIEdel, E. (Hrsg.), Gemeinsames Verfassungsrecht in der Europäischen Union, Nomos Verl., Baden-Baden, 1998, págs. 209-219, especialmente pág. 209.

19 O creando un nuevo sistema de entrada en vigor de los Tratados, sin que sean necesarias las ratificaciones de todos los EE.MM. En cualquier caso, es interesante recordar que Alemania ha hecho una propuesta en este sentido en la cumbre de Niza de diciembre de 2000. Propuesta que ha sido recogida en el anexo del Tratado de Niza.

20 Por eso no compartimos la tesis de Grimm, Frank-Dieter, «Braucht Europa eine Verfassung?", en Juristen Zeitung, 1995, págs. 581 y 590, cuando concibe 
ordenamientos han ido asumiendo un desarrollo común, cada vez más amplio, de materias.

Por eso, creemos que la autonomía, como cualidad del orden comunitario 21 , no debe ser entendida como autosuficiencia22, sino como interdependencia. Esta interdependencia se manifiesta en dos planos: 1) el derecho comunitario debe respetar los principios constitucionales que legitiman su existencia; y 2) el derecho nacional debe respetar el derecho comunitario elaborado conforme a estos principios. Es decir, el orden jurídico comunitario es "autónomo" en la medida en que es "constitucional ${ }^{23} y$, simultáneamente, los ordenamientos constitucionales de los EE.MM. de la Unión han dejado de ser «autónomos" en la medida en que han decidido gestionar en común, y por un tiempo indefinido 24 , una serie de materias, en el momento en que deciden que sean las instituciones comunitarias, a través de normativa comunitaria, las que las regulen ${ }^{25}$.

la constitución de la Unión como una Constitución nacional a través de la cual la Unión tendría la Kompetenz-Kompetenz.

21 El derecho comunitario fue denominado como "fuente autónoma» por elTJCE en su sentencia Costa/Enel, asunto 6/64, Rec. 1964, especialmente pág. 593 y esta denominación sirve a LINDAHL, Hans, y VAN RoERMUND, "Law without a State? On representing the Common Market», en The European Union and its Order. The legal theory of European Integration (BANKowskı, Zenon, y Scotr, Andrew, eds.), Blackwell, Oxford, 2000, pág. 1, para comenzar su trabajo con la siguiente pregunta: "Can the European Community be an autonomous legal order if he EC is not a political unity?».

22 Para BIEBER, Roland, «Verfassungsentwicklung der Europäischen Union: Autonomie oder Konsequenz staatlicher Verfassungsentwicklung?», en MüLLERGRAFF, P.-Ch., y RIEDEL, E. (Hrsg.), Gemeinsames Verfassungsrecht in der Europäischen Union, Nomos Verl., Baden-Baden, 1998, pág. 212: la «autonomía» de la Constitución de la Unión (Unionsverfassung) sólo puede significar su independencia (Selbständigkeit) del Derecho o del ordenamiento constitucional de los Estados miembros, individualmente considerados (eines einzelnen Mitgliedstaates).

23 HESSE, Konrad, "Deutsche Verfassungsgerichtsbarkeit an der Schwelle zum neuen Jahrhundert", en ScHWARZE, Jürgen (Hrsg.), Verfassungsrecht und Verfassungsgerichtsbarkeit im Zeichen Europas, Nomos Verlagsgesellschaft, BadenBaden, 1998, págs. 169-181, especialmente pág. 180, intentando tranquilizar al TC alemán, dice que el derecho constitucional y el comunitario al ser interdependientes no pueden prescindir el uno del otro.

24 Tanto el artículo 312 del TCE como el artículo 51 del TUE señalan que ambos Tratados se concluyen por un tiempo indefinido.

25 Como dice HäBERLE, Peter, "Gemeineuropäisches Verfassungsrecht», en SCHWARZE, Jürgen (Hrsg.), Verfassungsrecht und Verfassungsgerichtsbarkeit im Zeichen Europas, Nomos Verlagsgesellschaft, Baden-Baden, 1998, págs. 11-44, especialmente pág. 42: "En esencia ningún legislador constitucional (Verfassunggeber) puede negar hoy la dimensión europea de una Nación" (traducción nuestra). 
Ahora bien, esta situación no implica que los órdenes constitucionales hayan dejado de ser los pilares básicos de legitimación del orden comunitario. Este orden existe por voluntad constitucional y su desarrollo, por tanto, es constitucional, es decir, debe hacerse conforme a los principios constitucionales de los EE.MM. ${ }^{26}$, cuya validez ha traspasado las fronteras del Estado para servir de pauta de legitimación del derecho que emana de las autoridades comunitarias ${ }^{27}$.

En este contexto jurídico el tema que nos interesa analizar es el del control, tanto del derecho comunitario, como de las instituciones que lo crean, ya que, finalmente, es el control la característica fundamental del constitucionalismo.

\section{LOS MECANISMOSTRADICIONALES DE CONTROL CONSTITUCIONAL EN EL SISTEMA COMUNITARIO}

Constitucionalismo es sinónimo de limitación de los poderes por la ley $^{28}$ y eso significa esencialmente: 1) que en un Estado o en cualquier sistema de Gobierno el ejercicio del poder debe acatar los métodos Y procedimientos establecidos en la ley (la idea de constitución o ley fundamental); 2) que la estructura institucional debe asegurar que el poder esté separado en diferentes manos, que se controlen mutuamente y que cooperen (Gobierno mixto, separación de poderes o checks and balances), y 3) que la relación entre Gobierno e individuos debe estar regulada de tal manera que proteja los derechos básicos de éstos.

Si trasladamos estos elementos al sistema comunitario nos encontramos con lo siguiente:

26 Como dice elTC español en su dictamen de 1 de julio de 1992, se transfiere el ejercicio de la competencias pero no se puede disponer de la Constitución misma: «(se transfiere) el ejercicio de competencias ex Constitutione, modulándose asi, por tanto, el ámbito de aplicación, pero no el enunciado, de las reglas que las han instituido $y$ ordenadon.

27 El hecho de que haya Constituciones que posibiliten la primacia y el efecto directo del derecho comunitario como la holandesa (art. 94), o la portuguesa (art. 8.3), o aún en el caso de la irlandesa que en su art. 29.6 establece la supremacia del derecho derivado sobre la Constitución, no es óbice para pensar que tal derecho pueda ser contrario a los principios constitucionales.

28 Ver, por todos, BAX, C., y VAN DER TANG, G: "Theses on Control in Constitutional Lawn, en Zoethout, Carla M.; VAN DeR TANG, Ger, y AKKermans, Piet (eds.), Control in Constitutional Law, Martinus Nijhoff Publishers, Dordrecht, Boston, Londres, 1993, págs. 87-96. 
1) La idea de constitución o ley fundamental. Los tratados comunitarios se encargan de establecer los métodos y procedimientos para adoptar los actos jurídicos y los artículos 220 y 230 (en relación con los arts. 234 y 241) delTratado de la Comunidad Europea (TCE, desde ahora) otorgan al Tribunal de Justicia (TJ, desde ahora) la competencia de controlar la legalidad de dichos actos.

EITJ ha añadido, así lo señala en la sentencia Foto-Frost ${ }^{29}$, que este poder de control pertenece exclusivamente a su jurisdicción y que los tribunales nacionales no tienen la facultad de declarar la invalidez de los actos de los órganos comunitarios ${ }^{30}$.

2) La idea de que la estructura institucional debe asegurar que el poder esté separado en diferentes manos que se controlen mutuamente y que cooperen (Gobierno mixto, separación de poderes o checks and balances).

Desde antiguo se ha dicho que el sistema comunitario reconoce la separación de poderes, aunque lo haga de una manera sui generis. Los Tratados señalan qué instituciones y a través de qué procedimientos tienen la facultad de adoptar los actos jurídicos comunitarios $y$, en caso de conflicto de atribuciones, corresponde alTJ, aplicando los Tratados, decidir a quién corresponde dicha atribución ${ }^{31}$.

Los Tratados señalan también el reparto de competencias entre la Comunidad y los EE.MM. y los instrumentos para solucionar los posibles conflictos que puedan surgir entre ellos (recurso de anulación ${ }^{32}$, recurso de incumplimientos de las obligaciones comunitarias por parte de los EE.MM. ${ }^{33}$ que, una vez más, resolverá el TJ. pág. 4199.

29 Asunto 314/85, sentencia de 22 de octubre de 1987, Rec. de 1987,

30 Recordemos que el art. 234 b) delTCE da competencia alTC para pronunciarse, con carácter prejudicial, "sobre la validez e interpretación de los actos adoptados por las instituciones comunitarias y por el Banco Central Europeo", pues bien, en la sentencia Foto-Frost el TJ «mejora" la redacción del Tratado declarando que esta competencia pertenece exclusivamente a su jurisdicción, argumentando que dar entrada a los tribunales nacionales pondría en peligro la unidad del ordenamiento comunitario y el principio de seguridad jurídica (apartado 15).

31 Ver, por ejemplo, la sentencia de 26 de marzo de 1987, Asunto 45/86, Comisión/Consejo, Rec. 1987, pág. 1493, o la sentencia de 22 de mayo de 1990, asunto C-70/88, Parlamento/Consejo, Rec. 1990, 1-2041.

32 Arts 230 a 233 delTCE. un EM.

33 Art. 226 del TCE, a iniciativa de la Comisión; art. 227, a iniciativa de 
Por lo tanto, elTJ también tiene el monopolio a la hora de resolver conflictos de atribuciones y de competencias y también lo ha utilizado de una manera creativa ${ }^{34}$.

3) La idea de que la relación entre Gobierno e individuos debe estar regulada de tal manera que proteja los derechos básicos de éstos. La protección comunitaria de los derechos fundamentales ha sido objeto de una constante discusión dentro de la Unión Europea ${ }^{35}$. Aquellos que han soñado con un sistema constitucional europeo no han dejado de luchar por un catálogo de derechos comunitario, precisamente, por la importancia de este elemento para conseguir tal fin. Ese afán ha dado sus frutos a finales del 2000 en la Carta de los Derechos Fundamentales de la Unión Europea ${ }^{36}$, aunque todavía no se sabe cómo, a través de qué instrumento jurídico, deberá introducirse en el sistema comunitario ${ }^{37}$.

34 El antiguo art. 173 delTCE (el actual art. 230 sí lo prevé en su párrafo 3. ${ }^{\circ}$ ) no preveía legitimación activa del PE para interponer recursos por incompetencia, vicios sustanciales de forma (...), desviación de poder, etc. y elTJ entendió que esta falta de previsión era una laguna y dio al PE legitimación activa (únicamente para salvaguardar sus prerrogativas) en el asunto 294/83, Partido ecologista "Los Verdes» contra PE y amplió esta posibilidad al ámbito del Tratado Euratom (cuyo antiguo art. 146 tampoco la preveia) en la sentencia Chernobyl, asunto C-70/88, Rec. 1990, pág. I-2041.

35 Sobre este tema, y por todos, Salinas de Frias, A., La protección de los Derechos Fundamentales en la Unión Europea, Granada, 2000, y, especialmente, $\mathrm{REICH}$, Norbert, Bürgerrechte in der Europäischen Union: Subjektive Rechte von Unionsbürgern und Drittstaatsangehörigen unter besonderer Berücksichtigung der Rechtslage nach der Rechtsprechung des EuGH und dem Vertrag von Amsterdam, Nomos, Baden-Baden, 1999.

36 Su texto se puede encontrar en la siguiente dirección de Internet: http://ue.eu.int/df/default.asp?lang=es

37 Este debate se ha retrasado hasta la CIG del 2004. En este retraso creemos ver la prudencia de los EE.MM. $\gamma$ de las instituciones comunitarias, conscientes de un hecho: en cuanto la Comunidad tenga una Carta de Derechos con valor juridico vinculante, desaparecerán las razones expuestas por el TJ, en su dictamen 2/94 de 28 de marzo de 1996 para su adhesión al Convenio Europeo de Derechos Humanos (CEDH), por lo que, al menos en lo relativo a la protección de derechos, las instituciones comunitarias (incluidos los tribunales) podrán ser fiscalizadas por el Tribunal Europeo de Derechos Humanos. La Comisión ya ha planteado esta adhesión en dos documentos Doc. 559 (COM) y 564 (COM). citados por AlONSO GARCIA, Ricardo, "Articulación de las relaciones entre la Carta Europea de Derechos fundamentales de la Unión Europea y las Constituciones de los Estados Miembros", en las Jornadas organizadas por el IVAP y Eusko Ikaskuntza en San Sebastián el 18-V-2001 con el título de Carta Europea de Derechos. 
En cualquier caso, el art. 6.1 delTUE reconoce que el respeto de los derechos humanos $y$ las libertades fundamentales es uno de los principios en los que se basa la Unión ${ }^{38}$ y, también en este caso, quien tiene el monopolio a la hora de juzgar si la normativa comunitaria ha conculcado tal principio es el TJ y, también en este ámbito, su activismo ha sido notorio ${ }^{39}$.

Tras este somero análisis podemos decir que el sistema comunitario, aunque de una manera sui generis, cuenta con los mecanismos que configuran el control dentro del constitucionalismo. Pero, simultáneamente, podemos decir que estos mecanismos de control, a través de la intervención del Tribunal de Justicia, se han convertido en mecanismos "autónomos» de control, es decir, no encontramos en ellos ningún paralelismo con la definición del orden comunitario que hacíamos en el punto precedente. Es decir, si entendemos que el derecho comunitario, únicamente, es autónomo cuando es constitucional, echamos en falta un instrumento jurídico que materialice esta afirmación. Ya que los ordenamientos jurídicos de los EE.MM., aunque complejos en lo que atañe a su producción, deben respetar la Constitución y por eso echamos de menos la vertebración del control de constitucionalidad sobre la normativa comunitaria.

Y para crear esta vertebración podemos partir del respeto a los mecanismos de control establecidos $y$, por lo tanto, asumir la capacidad del Tribunal de Justicia (TJ) para ser el único intérprete del derecho comunitario, por lo tanto nos faltaría el mecanismo que asegure que el TJ, en sus interpretaciones, no vulnere ningún principio constitucional.

\section{LA IMPORTANCIA SOBREVENIDA DEL TRIBUNAL DE JUSTICIA}

Mientras la Comunidad continúe siendo una comunidad de derecho, su máxima autoridad es el derecho y quién lo define e interpreta es elTJ y así lo ha hecho a través de sus más de 5.000 sentencias, algunas de ellas muy criticadas. No es extraña la critica ya que, sin ningu-

38 Sobre el valor jurídico de estos principios se puede ver mi trabajo, de próxima publicación, "La importancia de la paulatina codificación de los principios generales del derecho comunitarion.

39 Un análisis más exhaustivo puede verse en mi trabajo "Los derechos fundamentales y el Derecho comunitario», en Cuadernos Europeos de Deusto, 18/1998, págs. 115-142. 
na duda, los jueces del TJ han sido algo más que la bouche qui prononce les paroles de la loi40. Estamos hablando del tribunal que ha sido calificado como el motor de la integración ${ }^{41}$, ya que la influencia de sus sentencias se ha extendido más allá de las competencias propiamente comunitarias ${ }^{42}$.

El TJ, a la hora de elaborar sus sentencias, muchas veces, no se ha basado directamente en una disposición ni de derecho originario ni de derecho derivado $y$, además, ha cambiado su propia jurisprudencia sin explicaciones de ningún tipo ${ }^{43}$. Este activismo del TJ ha hecho que esta institución haya llegado a ocupar un lugar preponderante, no sólo en el sistema de control del derecho comunitario, sino en el sistema de control del derecho interno de los EE.MM.

Como muestra de esta actitud expansiva que ha propiciado la jurisprudencia del TJ, haciendo que el derecho comunitario penetre en los sistemas constitucionales, más allá de lo exactamente establecido

40 Ningún juez es un autómata, sírvanos de ejemplo la manera en que se eligen los jueces de los Tribunales Constitucionales, el cuidado que pone en conseguir un equilibrio "político» entre sus miembros para encontrar una armonía de la balanza política. Por eso, y teniendo en cuenta las irónicas palabras de SHAPIRO, M. J., "Comparative Law and Comparative Politics", S. California Law Review, n." 53, 1980, págs. 537 y 538: "Constitutional law without politics... the European Community as a juristic idea; the written constitution as a sacred text; the professional commentary as a legal truth; the case law as the inevitable working out of the correct implications of the constitutional text and the [European Court of Justice] as the disembodied voice of right reason and constitutional theology...", ha llegado el momento de controlar la labor de este Tribunal.

41 Ver, entre otros, a STEIN, Torsten, «Richterrecht wie anderswo auch? Der Gerichtshof der Europäischen Gemeinschaften als "Integrationsmotor" ", en Richterliche Rechtsfortbildung, Festschrift der Juristischen Fakuität Heidelberg, Heidelberg, 1994, págs. 619-641.

42 Un aspecto de esta tendencia expansiva del derecho comunitario (a través de la jurisprudencia del TJ) en el interior de los ordenamientos jurídicos constitucionales puede verse en mi trabajo "Los "efectos colaterales" del derecho comunitario en la regulación constitucional de los derechos fundamentales", Comunicación presentada al Congreso del Centro de Estudios de Derecho del Estado con el título Derechos fundamentales y Estado Autonómico, celebrado en Barcelona y Tarragona, los dias 20-22 de octubre de 1999, de próxima publicación.

43 Sobre esta manera de actuar del TJ, ver un análisis más amplio en UkROw, Jörg, Richterliche Rechsforbildung durch den EuGH, Nomos, BadenBaden, 1995; en las págs. 187-189 compara los límites que tiene el desarrollo judicial del common law, a través del stare decisis, con la ausencia de límites del TJ. 
en el derecho comunitario originario y derivado, citaremos las recientes sentencias de 26 de octubre de 1999 (asunto C-273/97, Angela María Sirdar) y de 11 de enero de 2000 (asunto C-285/98, Tanja Kreil) ${ }^{44}$, ambas relacionadas con la discriminación que sufre la mujer para entrar en el ejército (en el Reino Unido y en Alemania, respectivamente). En estos casos, al margen de que, materialmente, podamos estar de acuerdo con la posición mantenida por el TJ, creemos que el Tribunal deja a un lado:

1) el hecho de que la seguridad del Estado pertenezca a la esfera de las competencias de los EE.MM.;

2) el hecho de que el art. 39.4 del TCE (el que regula la libertad de circulación de trabajadores y utilizado en los argumentos de las sentencias) establezca que "lo anteriormente expresado" no será aplicable a los empleos en la administración pública;

3) (en el caso Kreil) que el apartado 2 del art. 2 de la Directiva 76/207/CEE del Consejo, de 9 de febrero de 1976, relativa a la aplicación del principio de igualdad de trato entre hombres y mujeres en lo que se refiere al acceso al empleo, a la formación y a la promoción profesionales y a las condiciones de trabajo 45 permita una actuación discrecional de los EE.MM. ${ }^{46}$, aunque el apartado 2 del art. 9 les obligue a revisar sus decisiones ${ }^{47}$. Como resultado de la sentencia Kreil en Alemania se ha propuesto la reforma del art. 12a de su Constitución ${ }^{48}$.

44 Estas sentenciadas son analizadas por StREinz, Rudolf, "Frauen an die Front -Besprechung der EuGH-Urteile Sirdar und Kreil», en Deutsches Verwaltungsblatt, 1 de mayo de 2000, Heft 9, págs. 585-595.

45 DO L 39, pág. 40; EE 05/02, pág. 70.

46 «2. La presente Directiva no obstará la facultad que tienen los Estados miembros de excluir de su ámbito de aplicación las actividades profesionales y, llegado el caso, las formaciones que a ellas conduzcan, para las cuales, el sexo constituye una condición determinante en razón de su naturaleza o de las condiciones de su ejercicion.

47 En virtud del artículo 9, apartado 2, de la Directiva, "los Estados miembros procederán periódicamente a un examen de las actividades profesionales contempladas en el apartado 2 del artículo 2, con el fin de comprobar, teniendo en cuenta la evolución social, si está justificado mantener las exclusiones de que se trata. Deberán comunicar a la Comisión el resultado de tal examen".

48 Ver la propuesta ai respecto del 25 de octubre de 2000, hecha en el Bundestag (126. Sitzung) en la dirección de Internet: http://www.bundestag.de 
Estos ejemplos nos señalan que en su función de interpretación y de salvaguardia del derecho comunitario la trayectoria del TJ se ha caracterizado por su limitación de las competencias de los Estados (la primacia del derecho comunitario, el efecto directo, el efecto útil...) o, viceversa, por su apoyo a la integración supranacional ${ }^{49} \mathrm{Y}$ sus decisiones no siempre han contado con una base jurídica de claro enunciado en losTratados, por lo que su labor ha sido o bien tildada de contraria al principio de legalidad 50 , o bien aplaudida por la calidad de su gestión, en tanto en cuanto ha sabido cubrir las deficiencias del sistema comunitario ${ }^{51}$.

La necesidad de mejorar juridicamente la Comunidad parece ineludible, sobre todo, ante su aumento de competencias tras los Tratados de Maastricht y Amsterdam, cuyo desarrollo posibilita que el margen de actuación del TJ se vea incrementado, así como por la ampliación de la jurisdicción delTribunal de Primera Instancia (TPI desde ahora) que permite el art. 220 en relación con el art. 225.1 del TCE en su nueva redacción de Niza52.

Este incremento de los ámbitos del derecho "elaborado" por los jueces (recordemos la preeminencia juridica que tiene la labor de los

49 Stone SweEt, Alec, y CAPORASo, James, «From Free Trade to Supranational Polity: The European Court and Integration", en European Integration and Supranational Governance (SANDHOLTZ, Wayne, y STONE SWEET, Alec, eds.), Oxford University Press, Oxford, 1998, págs. 92-130, tras un estudio de la actividad delTJ, fundamentalmente, a través de sus resoluciones de cuestiones prejudiciales, llegan a la conclusión de que el Tribunal interpreta tanto el Tratado, como las obligaciones subsiguientes de los EE.MM., de forma expansiva (pág. 130).

50 Son muy interesantes las páginas que HARTLEY, Trevor C., Constitutional Problems of the European Union, Hart, Oxford and Portland, Oregon, 1999, págs. 24-42 dedica al estudio de las grandes sentencias del TJ y de su estudio se desprende la conclusión de la pág. 36: "It also makes clear that the Court is prepared to go against the Treaties where it feels that the constitutional development of the Community so requires». Algo más adelante, en la pág. 41, añade que elTJ es consciente de que sus sentencias van más allá de los Tratados y señala que su tendencia es la de incrementar los poderes de la Comunidad «in general and those of the Court itself in particular".

51 Por todos ver De FARIŃÁN GILBert, Juan Manuel, «El Tribunal de Justicia en losTratados de Maastricht y de Amsterdam: una visión comparativa", en De FARiNÁN GILBERT, Juan Manuel (coord.), Reflexiones en torno al Tratado de Amsterdam $y$ el futuro de la Unión Europea, Ed Comares, Granada, 2000, pág. 189: "(...) se trata de una de las instituciones comunitarias que con más acierto ha cumplido con las funciones encomendadas por los tratados constitutivos».

52 Las novedades introducidas en el Tratado de Niza pueden verse en YATAGANAS, Xenophon A., "The Treaty of Nice. The Sharing of Power and the Institutio- 
jueces delTJ y delTPI) se hace sin que tal vía cuente con el respaldo de una cimentada tradición histórica en los EE.MM., más bien al contrario ${ }^{53}$, ni con la aquiescencia expresa de los ciudadanos (las ratificaciones necesarias de los Tratados, únicamente, en Dinamarca exigen un referéndum $)^{54}$. $Y$ esto ocurre, paradójicamente, mientras se está pidiendo una función más estrictamente jurídica que política para el TJ55.

De todas las funciones del TJ nos merece especial atención, su papel en la resolución de conflictos de competencias entre los EE.MM. $y$ las instituciones comunitarias. $Y$ entendemos que pueden pertenecer a este ámbito sentencias del $T J$ que, formalmente, se están ocupando de interpretar el derecho comunitario.

En los ámbitos de competencia exclusiva de la Comunidad, los EE.MM. han aceptado, implícitamente, la exclusividad de la jurisdicción delTJ, en su función de interpretación y de salvaguardia del derecho comunitario, en el momento en que ratifican los Tratados que las prevén. Por lo tanto, en ese ámbito únicamente cabe criticar la actuación del Tribunal desde un punto de vista doctrinal.

$Y$ en este terreno doctrinal podemos decir: 1) que su trayectoria se ha caracterizado por su limitación de las competencias de los

nal Balance in the European Union-A Continental Perspective", Harvard Jean Monnet Working Paper 1/2001, que puede conseguirse en la dirección de Internet: http://www.jeanmonnetprogram.org/papers/01/010101.html, más exactamente en http://Www.jeanmonnetprogram.org/papers/01/010101-04.html\#P607_130370 pueden verse los posibles efectos de la nueva estructura judicial comunitaria.

$53 \mathrm{El}$ derecho de creación judicial (Richterrecht) pertenece, tradicionalmente, a la realidad jurídica de todos los Estados miembros, siendo el Reino Unido el que cuenta con una tradición más extensa, pero también alli el Common Law ha sido paulatinamente desbancado por el Statute Law. Ver ZiMmERMANN, Reinhard, "Statuta sunt stricte interpretanda? Statutes and Common Law: A Continental Perspective", en Cambridge Law Journal, 56 (1997), pág. 315.

54 De acuerdo con el art. 42 de la Constitución danesa para ratificar los Tratados se exige, alternativamente, o el voto afirmativo de los cinco sextos del Parlamento o la mayoria de los votos en un referéndum nacional.

55 En este sentido se expresa EVERLING, Ulrich, "Die Gerichtsbarkeit in der erweiterten Europäischen Union» en SCHWARZE, Jürgen (Hrsg.), Verfassungsrecht und Verfassungsgerichtsbarkeit im Zeichen Europas, Nomos Verlagsgesellschaft, Baden-Baden 1998, págs. 199-222, especialmente, pág. 201 y la razón más importante para ello es, según este autor, la ampliación (p. 202). En el mismo artículo se pueden encontrar sus propuestas para hacer frente a la ampliación. 
Estados (la primacia del derecho comunitario, el efecto directo, el efecto útil...);2) o que el principio del self restraint, que acompaña a los Tribunales de los Estados constitucionales (con menores poderes de decisión en el sentido de que su actuación está más limitada), es un principio perfectamente desconocido por elTJ. También es posible criticarlo porque sus decisiones no siempre han contado con una base jurídica de claro enunciado en los Tratados, por lo que han sido tildadas, en numerosas ocasiones, de contrarias al principio de legalidad, máxime cuando, a veces, desconoce la doctrina del stare decisis, consustancial a los principios de equidad, seguridad juridica y confianza legítima ${ }^{56}$.

Ahora bien, en el ámbito de las competencias exclusivas de la Comunidad, aunque las criticas sean posibles, el TJ tiene el monopolio para controlar la legalidad de los actos jurídicos comunitarios, porque los órganos constitucionales de los EE.MM. le han dado ese poder en el momento de ratificar el Tratado comunitario que reconoce la transferencia de esas materias a la Comunidad. Su único límite es que debe tener en cuenta los principios constitucionales de los EE.MM. a la hora de elaborar su sentencia. Porque, como hemos dicho, el orden comunitario sólo es autónomo en la medida en que los respeta. Aunque, una vez tenidos en cuenta, el contenido de dichos principios constitucionales puede sufrir variaciones en la jurisprudencia delTJ.

No se trata de utilizar planteamientos genéricos como el de la jurisdicción universal de los Tribunales Constitucionales ${ }^{57}$, porque creemos que los sistemas constitucionales asumen, al ratificar los Tratados que dan competencias exclusivas a la Comunidad, un desarrollo de esas competencias diferente al nacional. En el mismo sentido, creemos que es contrario a derecho pretender retomar competencias cedidas argumentando que la producción de la normativa comunitaria adolece de déficit democrático. El momento de discutir

56 Un ejemplo puede ser el cambio de jurisprudencia entre la sentencia del asunto C-450/93, Kalanke v. Bremen, Rec. 1995, pág. I-3051 y la sentencia del asunto C-409/95, Marshall v. Land Nordrhein-Westfalen, Rec. 1997, pág. 1-6363.

57 La justificación de tal doctrina es la siguiente: Soberanía significa que toda ley aplicable en un Estado lo es en base a la Constitución de ese Estado y la misma Constitución señala que el Tribunal Constitucional (en su caso) es el árbitro final de las cuestiones concernientes al derecho constitucional. Por eso este tribunal tiene la última palabra sobre cualquier acto legislativo sea nacional, internacional o supranacional. 
esos temas es el momento de la ratificación de los Tratados comunitarios pero, una vez asumidos, el sistema constitucional interno de cada EM asume el desarrollo comunitario de dichas materias. El único argumento jurídico posible contra ese desarrollo normativo es, como hemos dicho, el de la vulneración de algún principio constitucional$\left.\right|^{58}$ o el de carecer de base juridica suficiente para desarrollar esa materia 59 .

\section{El posible control de constitucionalidad sobre el derecho derivado comunitario y sobre la jurisprudencia del TJ}

Mientras en los ámbitos de competencia exclusiva de la Comunidad resulta constitucionalmente válido que el TJ tenga la última palabra, en los ámbitos de competencia concurrente creemos que la jurisdicción exclusiva del TJ resulta, no sólo discutible, sino inconstitucional. La base jurídica de nuestros argumentos descansa, además de en los sistemas constitucionales, en los siguientes artículos de los Tratados:

1) El art. 6.3 del TUE: la Unión respetará la identidad nacional de sus EE.MM.;

2) El art. 5 delTCE: La Comunidad actuará dentro de los límites de las competencias que le atribuye el presente Tratado (...) y ninguna acción de la Comunidad excederá de lo necesario para alcanzar los objetivos; $y$

58 Como dice КUмm, Mattias, "Who is the Final Arbiter of Constitutionality in Europe? Three Conceptions of the Relationship between the German Federal Constitutional Court and the European Court of Justice and the Fate of the European Market Order for Bananas», Internet: http://www.jeanmonnetprogram.org/papers/98/98-10-html: "Therefore the important question seems to be not whether the Member States Courts have jurisdiction over secondary EC legislation, but whether and how they ought to exercise the jurisdiction they claim to have in fact".

59 En el mismo sentido BverfGE 98, 188: «(...) en consecuencia (el Tribunal Constitucional alemán) examinará si los actos jurídicos de las instituciones u órganos europeos se mantienen en los límites de los derechos de soberania a ellos cedidos o los transgreden". 
3) Los artículos $220^{60}$ y $234^{61}$ del TCE.

El art. 6.3 del TUE al reconocer la identidad de los EE.MM. reconoce sus sistemas constitucionales, con lo que permite a éstos interactuar con el sistema comunitario y esta posibilidad tiene su máximo sentido a la hora de dar contenido al art. 5 del TCE, artículo que también obliga al propio TJ62. Entendemos que cuando el TC alemán y el TS danés se niegan a aplicar derecho comunitario que exceda a las competencias previstas en los Tratados, por mucho que el TJ lo considere válido («lega|»), están llamando la atención sobre la ausencia de límites del TJ63. Parece claro admitir que el TJ no puede tener el monopolio en la decisión sobre ámbitos en los que la Comunidad no tiene tal monopolio (competencia exclusiva).

Por lo tanto, los órganos constitucionales de los EE.MM. sí que pueden controlar que el derecho comunitario no sobrepase los límites de las competencias previstas en los Tratados (control negativo). Pueden, por tanto, emitir su opinión sobre los límites del art. $5^{64}$ y esta opi-

60 «El Tribunal de Justicia y el Tribunal de Primera Instancia garantizarán, con arreglo a sus respectivas competencias, el respeto del Derecho comunitario en la interpretación y aplicación del presente Tratado" (la cursiva es la modificación introducida en el Tratado de Niza).

61 Del art. 234, el que dice que «el TJ será competente para pronunciarse con carácter prejudicialı, nos interesan especialmente las siguientes epígrafes: a) sobre la interpretación del presente Tratado y b) sobre la validez e interpretación de los actos adoptados por las instituciones de la Comunidad. El Tratado de Niza, en el art. 225.3 amplía la competencia del conocimiento de cuestiones prejudiciales al Tribunal de Primera Instancia.

62 En ese sentido el TJ ha sido juez y parte hasta este momento.

63 El Tribunal Constitucional alemán en su sentencia sobre el Tratado de Maastricht (de 12 de octubre de 1993, BvR $2134 / 92$ y BvR 2159/92, BverfGE 89, 155) y el Tribunal Supremo danés (sentencia de 6 de abril de 1998, asunto I 361/1997, Carlsen contra Rasmussen) ponen en tela de juicio esta capacidad delTJ y se arro-gan la capacidad de controlar los actos comunitarios que vayan más allá de las competencias de la Comunidad. En esta discusión no estamos de acuerdo con la doctrina que sostiene que elTC alemán no puede reivindicar esta posición, entre otros EVERLING, Ulrich, Bundesverfassungsgericht und Gerichtshof der Europäischen Gemeinschaften. Nach dem Maastricht-Urteil. Gedächtnisschrift für Eberhard Grabitz, München, 1995, págs. 57 y 71, aunque nosotros matizamos que este control es sólo posible: 1) en las competencias concurrentes; 2) cuando la normativa o la decisión delTribunal han dejado sin contenido un principio constitucional; y 3) cuando no existe una base jurídica clara en los Tratados en la que apoyar la norma o la resolución judicial.

64 Los órganos constitucionales de los EE.MM. son los que mejor pueden calibrar si se ha hecho un buen uso del principio de subsidiariedad, ya que este 
nión es, al menos tan válida como la del TJ, máxime cuando los citados artículos 220 y 234 del TCE no le dan ninguna competencia exclusiva en sus mandatos.

En resumen, elTJ mantiene su jurisdicción única controlando la legalidad de los actos jurídicos comunitarios, siempre que éstos actos hayan superado el control de constitucionalidad de los EE.MM. Incluso las sentencias, sin una clara base jurídica de la que se desprendan sus argumentos, deberían ser susceptibles de este control de constitucionalidad.

\subsection{Las dificultades de la vertebración jurídica de un mecanismo compartido de control}

Con la minoración que el principio de democracia padece en el sistema comunitario a la hora de la elaboración del derecho, creemos que en el modelo actual el TJ asume una excesiva responsabilidad en su tarea de dar contenido a los principios de libertad, respeto de los derechos humanos y libertades fundamentales y Estado de Derecho (art. 6.1 del TUE), en los cada vez más amplios ámbitos de su competencia65. Además la interdependencia entre ordenamientos, de la que partimos, exige una mayor presencia de los guardianes de los sistemas constitucionales en el entramado comunitario, de tal manera que, por medio del debate entre todas las instancias, pueda darse una respuesta comunitario-constitucional a los conflictos planteados.

El vacio de control que detectamos es el que se refiere a asegurar que las instituciones comunitarias no asuman competencias que no tienen, o no hagan un uso «inconstitucional» de las que tienen. Las batallas juridicas en torno a la primacía del derecho comunitario siempre comienzan cuando los órganos encargados del

principio, tan estudiado doctrinalmente, parece no haber aportado mucho a la autolimitación de la producción jurídica comunitaria.

65 No vamos a analizar en este trabajo ni la composición delTJ ni la ausencia de un telos claro a la hora de tomar sus decisiones inapelables y obligatorias para todos. Estos problemas son tratados por EVERLING, Ulrich, "Richterliche Rechsfortbildung in der Europäische Gemeinschaft", en Juristen Zeitung 5/2000 (de 3 de marzo), págs. 217-227, especialmente págs. 222-223; interesante, también, la bibliografía allí citada. 
control de constitucionalidad en los EE.MM. opinan que las autoridades comunitarias (TJ incluido) han ido más allá de sus competencias, en el sentido de normar un ámbito que no les pertenece: 1) porque formalmente no tienen la competencia; o 2) porque teniendo la competencia formal, el contenido material de la norma se introduce "colateralmente" en la regulación de espacios de competencia estatal.

Pero una definición clara de competencias no resulta fácil en el sistema creado por los Tratados comunitarios ${ }^{66}$, ya que, hasta el momento, no se ha concebido siguiendo el sistema europeo de los Estados compuestos, es decir, el de listas de competencias (exclusivas o concurrentes), sino que se ha utilizado otra vía: nombrar un objetivo general para cuya consecución las instituciones comunitarias se apropiarán de las competencias necesarias (art. 308 TCE) ${ }^{67}$. Por eso resulta un sistema tan invasor y por eso se ha encontrado con la oposición de tribunales constitucionales, acostumbrados a trabajar dentro de otras pautas jurídicas.

Y para ser realistas, parece bastante impensable que, a estas alturas, el sistema comunitario retome el sistema tradicional de reparto de competencias de los Estados ${ }^{68}$, aunque habrá que ver cual es el futuro de la petición alemana en este sentido, recogida en el punto 5 de la Declaración final sobre el futuro de la Unión que acompaña al Tratado de Niza ${ }^{69}$. Indudablemente, hay mecanismos que pueden cla-

66 La delimitación de las competencias de la Unión es un tema muy complejo, tras el cual no sólo se encuentran los poderes centrales de los EE.MM. sino los regionales y los locales. En este sentido ver SCHWARZE, Jürgen, "Kompetenzverteilung in der Europäischen Union und föderales Gleicgewicht -Zu den Forderungen der deutschen Bundesländer im Hinblick auf die Regierungskonferenz 1996-», en Deutsches Verwaltungsblatt, 1995, págs. 1265 y ss.

67 García de ENTERRIA, Eduardo, "El proyecto de Constitución europea", Revista Española de Derecho Constitucional, n. ${ }^{\circ} 45,1995$, págs. 9-29, especialmente págs. 25-29, detecta una similitud entre el antiguo art. 235 del TCE (actual art. 308) y la "cláusula de comercio» del art. I, sección 8, apartado 3 de la Constitución de EE.UU.

68 Sobre este tema ver VETTER, E., «Kompetenzverteilung zwischen der Europäischen Union und den Mitgliedstaaten aus der Sicht der deutschen Ländern, en MAGIERA, Siegfried y Siedentopf, Heinrich (Hrsg.), Die Zukunft der Europäischen Union, Duncker \& Humblot, Berlín, 1997, págs. 23, 32 y ss.

69 El contenido de este punto es el cómo establecer y supervisar una delimitación más precisa de competencias entre la UE y los EE.MM. que refleje el principio de subsidiariedad. El punto 7 de la misma declaración establece la creación 
rificar el sistema actualmente existente ${ }^{70}$, ya que, desde nuestro punto de vista, resulta "constitucionalmente" necesario que cualquier transferencia de tareas a la Comunidad, o cualquier utilización de competencias normativas nuevas deba ser controlada.

El problema estriba en cómo resolver los conflictos emanados de esta concurrencia de competencias ${ }^{71}$, ya que, un mismo acto puede ser considerado nulo en unos Estados y válido en otros ${ }^{72} y$ ante este resultado:

1) Como estamos hablando de competencias concurrentes, podemos entender que esta situación no va en contra de los principios del derecho comunitario en la medida en que los propios Tratados prevén la cooperación reforzada (arts. 40 y ss. del TUE y art. 11 del TCE), cooperación que implica una ruptura en la uniformidad del derecho comunitario; por to tanto, se podría aceptar, sin mayores complicaciones, que haya parte del derecho comunitario que no tenga validez en todo en territorio de la Unión ${ }^{73}$;

2) En la medida en que buscamos la interacción entre ordenamientos, los Tratados podrían establecer mecanismos que la posibiliten, evitando así la disparidad de criterios. Weiler y Haltern proponen la creación de una especie de Consejo Constitucional Europeo, formado por los presidentes de los Tribunales Constitucionales de los EE.MM. (u órganos asi-

de una Conferencia de Representantes de los Gobiernos de los EE.MM. par tratar, entre otros, este tema en el año 2004.

70 Uno de ellos puede ser el de utilizar el camino de la prohibición de materias objeto de competencia comunitaria.

71 EITJ es competente sólo cuando el derecho comunitario es constitucionalmente correcto y quienes pueden decidir eso son los órganos de los EE.MM. encargados del control de constitucionalidad.

72 Éste es el argumento básico que han utilizado tanto el TJ como la doctrina (ver por todos Slaughter, Anne-Marie; Stone Seet, Alec, y Weiler, Joseph H. H. (eds.), The European Courts and National Courts, Doctrine and Jurisprudence: legal chance in its social context, Hart, Oxford, 1998, donde se recogen las posiciones mantenidas en varios EE.MM. sobre este tema.

73 WALKER, Neil, "Sovereignity and Differentiated Integration in the European Union", en Bankowskı, Zenon, y Scott, Andrew (eds.), The European Union and its Order. The legal theory of European Integration, Blackwell, Oxford, 2000, págs. 31-64 estudia los problemas que plantea tal situación y concluye diciendo que habrá que buscar respuestas diferentes a las acostumbradas para órdenes políticos menos complejos. 
milados) y presidido por el presidente del TJ para que dirimiese estas cuestiones en caso de plantearse ${ }^{74}$. En esta propuesta, el control se haría antes de que la norma entrase en vigor, pero desde nuestro punto de vista, este tipo de control excluiría del mismo al TJ y por eso pensamos que el Consejo Constitucional Europeo debería dirimir tanto conflictos ex ante como ex post. De esta manera: 1) el TJ contaría con otra jurisprudencia, diferente a la propia, para tomar sus decisiones ${ }^{75}$; 2) el TJ se vería limitado desde los Tratados para elaborar sus decisiones, que deberían estar basadas en mandatos concretos de los mismos, para evitar un control ulterior; y 3) finalmente, nuevos órganos constitucionales de los EE.MM. (en este caso los Tribunales Constitucionales) podrian intervenir más activamente en la elaboración y en el control del derecho comunitario. En cuanto a la legitimación activa, la ex ante podía corresponder tanto a instituciones comunitarias como estatales y la legitimación activa ex post para plantear la duda sobre la constitucionalidad de una norma o de una sentencia delTJ, debería recaer en los tribunales nacionales, cuya vinculación a los mandatos constitucionales está prevista en los propios textos

74 Ver WeILER, J. H. H., y HALTERN, Ulrich R, «Reponse: The Autonomy of the Community Legal Order-Through the Looking Glass", Harvard International Law Journal, 37/1996, págs. 346 y ss., o la versión revisada de este artículo que aparece en Slaughter, Anne-Marie; Stone SWeEt, Alec, y WeILER, Joseph H. H. (eds.), The European Courts and National Courts, Doctrine and Jurisprudence: legal chance in its social context, Hart, Oxford, 1998, y que llega como título "Constitutional or International? The foundations of the Community Legal Order and the Question of Judicial Kompetenz-Kompetenz", págs. 364 y ss. El modelo propuesto se basa en el Consejo Constitucional francés y se piensa que su actuación debe ser previa a la entrada en vigor del acto normativo. Estos trabajos se basan en un debate entre SchiLLING, Theodor; WeILER, Joseph H. H., y HALTERN, Ulrich R., publicado por Cambridge Harvard Law School, 1996, con el título de "Who, in law, is the ultimate judicial umpire of European Community competences? The Schilling-Weiler/Haltern debate", Harvard Jean Monnet working papers, 10/96, que puede encontrarse en la siguiente dirección de Internet: http://www.jeanmonnetprogram.org/papers/96/9610.html. La misma idea es ampliada en el artículo de WEILER, "The Reformation of European Constitutionalism", Journal of Common Market Studies 35, 1997, págs. 97-131.

75 Sobre este tema ver ARNULL, Anthony, "Owning up to fallibility: Precedent and the Court of Justice", Common Market Law Review, 30/1993, págs. 247266, y PLendeR, Richard (ed.), European Courts: Practice and Precedents, Sweet \& Maxwell, Londres, 1997. 
constitucionales, siendo de esta manera jueces comunitarios $^{76}$, a la vez que constitucionales.

3) En lugar de crear un nuevo órgano se podria buscar una versión europea de la doctrina del our federalism estadounidense 77 , basada en reglas de "deferencia entre tribunales" 78 , de tal manera que elTJ pudiese considerar válida una norma comunitaria con dudas razonables de constitucionalidad en un EM, únicamente, cuando surgiesen cuestiones que trascendieran el caso concreto. La nueva organización delTJ, hecha en el Tratado de Niza (art. 221 delTCE en relación con el apartado $3 .^{\circ}$ del art. 16 del Estatuto del TJ $)^{79}$, permitiría que una sentencia de una Sala o de la Gran Sala, considerada inconstitucional en un EM, pudiese reenviarse al Pleno, para que la institución pudiese cambiar el fallo, teniendo en cuenta las alegaciones

76 Debido al efecto útil del derecho comunitario, según la jurisprudencia del $\mathrm{TJ}$, se instaura un control difuso de "comunitariedad" sobre las normas nacionales, en cuya cúspide está el propio TJ que, asimismo, recuerda que no es necesaria ni conveniente la participación de los Tribunales Constitucionales en este control. Según la jurisprudencia establecida en la sentencia Simmenthal y mejorada en la sentencia Foto-Frost un juez nacional podrá no aplicar una ley interna por considerarla contraria al derecho comunitario $y$, en cambio, no podrá hacer lo mismo si la considera contraria a la Constitución. Como señala FERSTENBERT, J., "L'application du droit communautaire et la situation constitutionnelle du juge national", Revue Trimestrielle de Droit Europèen, 1/1979, págs. 32 y ss., especialmente pág. 43, la situación en la que esta jurisprudencia coloca al juez nacional es bastante delicada, ya que se ve obligado a considerar como inexistente la norma interna, e incluso se ve formalmente invitado a desconocer, para asegurar la primacía del derecho comunitario, las normas constitucionales que determinan la solución de conflictos.

77 Doctrina citada por VIRGALA ForURIA, Eduardo, "Control abstracto y recurso directo de inconstitucionalidad en los Estados Unidos", Revista española de Derecho Constitucional, n. ${ }^{\circ} 62$, mayo-agosto 2001, págs. 77-124; para mayor comprensión de esta doctrina, el autor nos remite a RuIz, Gregorio, Federalismo judicial (EI modelo americano), Civitas, Madrid, 1994, pág. 126, y a NowaK, John E., Y Rotunda, Ronald D., Constitutional Law, 5. ${ }^{a}$ ed., West Publishing Co., St. Paul (Minn.), 1995, pág. 103.

78 Explica el profesor VIRGala, ibidem, que este principio servía para que los tribunales estatales determinasen si las leyes estatales eran o no constitucionales y por lo tanto se impedía que mediante interdictos federales se paralizasen procesos ya comenzados ante tribunales estatales.

79 «EITJ se constituirá en Gran Sala cuando lo solicite un EM o una institución de la Comunidad que sea parte en el proceso" establece el apartado. $3 .^{\circ} \mathrm{del}$ art. 16. 
constitucionales del (o de los) EM inmerso(s) en el conflicto ${ }^{80}$. En definitiva, se trataria de establecer los mecanismos que posibilitasen un diálogo permanente entre la máxima instancia judicial comunitaria y la máxima instancia constitucional de cada $\mathrm{EM}^{81}$, diálogo necesario para, en última instancia, asegurar un desarrollo constitucional del derecho comunitario.

\section{RECAPITULACIÓN}

1) El sistema comunitario, como sistema nacido al amparo del derecho internacional, depende de los sistemas constitucionales de los EE.MM., de los que deriva su legitimidad;

2) Los mecanismos de control del sistema comunitario reproducen embrionariamente, los de los Estados constitucionales;

3) Los ordenamientos constitucionales aunque, formalmente, siguen manteniendo su posición de ordenamientos originarios han perdido el poder de controlar el ordenamiento comunitario y éste, aunque, formalmente, mantiene su posición de ordenamiento derivado, es quien tiene el poder de controlar los ordenamientos nacionales (una paradoja) ${ }^{82}$;

80 Esto supondría la modificación del último párrafo del art. 16 del Estatuto del TJ que establece los siguiente: «Asimismo cuando considere que un asunto del que conozca reviste una importancia excepcional, elTribunal podrá decidir, una vez oido el abogado general, la remisión del asunto al Plenon; de tal manera que se ampliase la posibilidad de reunir al pleno a los máximos intérpretes constitucionales de los EE.MM. cuando una sentencia del TJ careciese de la base jurídica suficiente para considerarla constitucionalmente aceptable.

81 En el trabajo del profesor GUTIÉRREZ GUTIÉRREZ, Ignacio, "Un orden jurídico para Alemania y Europan, Teoria y Realidad Constitucional, n. 3, 1999, págs. 215-223, especialmente págs. 222-223, puede encontrarse un claro resumen de otras vías para establecer este diálogo de jurisdicciones.

82 Como dice Everson, Michelle, "Beyond the Bundesverfassungsgericht: On the necessary cunning of Constitutional Reasoning", en BANKOWSKI, Zenon, $y$ Scotr, Andrew (eds.), The European Union and its Order. The legal theory of European Integration, Blackwell, Oxford, 2000, pág. 92: "The dynamic European policy is thus not only characterised by an intrincate scheme of multiple and formally sovereign national collectivities on the one hand, and (de facto) autonomous European institutions on the other (...)". 
4) En el ámbito de competencias de la Comunidad no se admiten los mecanismos internos de control: a) los Parlamentos nacionales apenas controlan a su Gobierno y mucho menos a las instituciones comunitarias; b) los jueces nacionales son jueces comunitarios, en la medida en que pueden controlar directamente que la legislación nacional no se oponga a la comunitaria ${ }^{83}$, pero no tienen el poder de controlar, al menos directamente, que la legislación comunitaria contravenga la nacional; y c) no se admite que los máximos intérpretes de la Constitución de los EE.MM. tomen parte en los sistemas de control comunitarios.

Obviamente, teniendo en cuenta de la situación descrita, podemos decir que los actuales sistemas constitucionales de los EE.MM. de la Unión, están inmersos en un proceso de integración supranacional cuya característica manifiesta es la minoración del contro| 84 (tanto politico, como jurídico).Y esta situación es contraria a los principios constitucionales, si entendemos que el derecho comunitario es un desarrollo del derecho constitucional ${ }^{85}$.

Si el derecho comunitario fuese, siguiendo la jurisprudencia del TJ, un único ordenamiento juridico (un nuevo orden jurídico) en el que los Tratados son la máxima fuente del derecho y que, en caso de conflicto, prevalecen sobre el derecho nacional, estariamos admitiendo

83 La aplicación directa del derecho comunitario por parte del Juez nacional parte de la sentencia de 9 de marzo de 1978 Simmenthal, asunto 106/77, Rec. págs. 629 y ss. y la idea de que no es necesario pedir o esperar la derogación previa de una disposición de derecho nacional contraria al derecho comunitario, sino que es papel del juez inaplicarla de oficio, es reiterada en la sentencia de 11 de julio de 1989, Ford España, asunto 170/88, apartado 19.

84 En un interesante trabajo, MAESTRO BUELGA, Gonzalo, "Globalización y Constitución débil», Teoría y realidad constitucional, n. ${ }^{\circ}$, 2001, págs. 137-172, señala que la pérdida del papel central de la Constitución es estructural en el momento actual $y$, por lo tanto, desde la caracterización que este autor hace de la "globalización", la Unión Europea no sería más que el instrumento concreto que hace posible que el sistema de fuentes se redefina en torno al ordenamiento en lugar de en torno a la Constitución.

85 Cabría esta posibilidad si el derecho comunitario fuese derecho internacional. Recordemos que la Comunidad es calificada como una organización internacional sui generis, cuyo desarrollo puede llevarla a otra condición jurídica PHELAN, Diarmuid Rossa, Revolt or Revolution: The Constitutional Boundaries of the European Community, Round Hall P., Dublín, 1997, pág. 30 y ss, siguiendo esta línea de evolución recoge los casos en los que un Tratado internacional ha dado origen a un nuevo Estado. 
que los Estados constitucionales, al ratificar los Tratados comunitarios han admitido poner en marcha un proceso cuyo único final es su propia disolución, en la medida en que han admitido vaciarse de competencias y han admitido que el desarrollo de las competencias cedidas escape al control constitucional. Es decir, no estariamos ante una apertura constitucional, sino ante un vaciamiento constitucional ${ }^{86}$.

Si aceptásemos que el derecho comunitario es, como postula el TC alemán, únicamente, parte del derecho internacional, es decir, del derecho que se produce fuera del orden constitucional nacional, que no es superior a la Constitución sino que es válido, precisamente, porque la Constitución lo permite, de acuerdo con sus previsiones de cooperación internacional87, estaríamos aceptando la existencia de dos ordenamientos diferenciados $y$, por lo tanto, en última instancia aceptaríamos la autonomía inmediata, aunque no mediata, del ordenamiento comunitario de la Constitución ${ }^{88}$. Estaríamos apoyando, en

86 Dos visiones opuestas sobre el futuro de la Unión pueden verse en MANCINI G. Federico versus WEILER, J. H. H., «Europe - The Case for Statehood... and the Case Against An Exchange", en Harvad Jean Monnet Working Paper 6/98, trabajos que pueden encontrarse en la siguiente dirección de Internet: http://www.jeanmonnetprogram.org/papers/papers98.html

87 El TC español también consideró los Tratados derecho internacional y dejó bien claro su sometimiento a la Constitución, sometimiento garantizado por el propio Tribunal tanto ex ante como ex post; y en su Dictamen de 1 de julio de 1992 sobre elTUE, especifica el carácter general del art. 95 de la Constitución (cuyo punto 1 dice que "la celebración de un tratado internacional que contenga estipulaciones contrarias a la Constitución exigirá la previa revisión constitucional'), es decir, que sus palabras también se aplican a los Tratados previstos en el art. 93. Añade que la previsión del art. 93 no puede utilizarse como «instrumento para contrariar o rectificar mandatos o prohibiciones contenidos en la Norma fundamental" y señala además que tal precepto no es un cauce legítimo para la reforma implícita o tácita constitucional. De este tema se ocupa LOPEZ BASAGUREN, Alberto, "¿Réquiem por la Constitución? El ordenamiento constitucional en la integración comunitaria", Civitas Europa, n. ${ }^{2}$, marzo 1999, págs. 7-30, especialmente págs. 9-10.

88 Precisamente porque el contenido del derecho internacional escapa más si cabe del control de constitucionalidad, sírvanos de ejemplo los acuerdos de algunos de los EE.MM. de la Unión dentro del Convenio de Schengen (relaciones intergubernamentales) han sido especialmente controladas por los sistemas constitucionales de los Estados que han formado parte de él. Esta ausencia de control $y$ sus consecuencias pueden verse en mi trabajo "Derechos fundamentales y Unión Europea. La necesidad de creación de un sistema de garantias para los derechos fundamentales en la Unión Europea: un ejemplo de los peligros de su ausencian, en García Herrera, Miguel Ángel (dir.), El constitucionalismo en la crisis del Estado social, UPV, Bilbao 1997, págs. 119-138. 
definitiva, una posición en la que el derecho constitucional mantiene su preeminencia formal pero, materialmente, acepta implementar normas de dudosa constitucionalidad.

Desde nuestro punto de vista, el derecho comunitario no es ni un ordenamiento autónomo ni tampoco parte del derecho internacional. Creemos que en esta segunda visión se confunden instrumento (elTratado un instrumento de derecho internacional) y contenido (decisión de desarrollar en común competencias constitucionales). El origen del derecho comunitario es internacional, pero su desarrollo deviene constitucional por el carácter constitucional de su contenido. Por eso se convierte en una fuente autónoma del derecho, únicamente: 1) si se elabora sobre la base de una competencia exclusiva; y 2) si respeta los principios constitucionales de los EE.MM.

Porque los EE.MM. han decidido poner unas materias en manos de las instituciones comunitarias, pero en ningún momento han decidido que la regulación de tales materias pudiese contravenir sus propios principios constitucionales ${ }^{89}$, en ese sentido mantienen la competencia de control "negativo" sobre el derecho comunitario que emana de una competencia exclusiva ${ }^{90}$. En el caso de las competencias concurrentes, el control podría ser tanto "positivo" como "negativo", porque aunque los Tratados prevean la posibilidad de que las instituciones comunitarias desarrollen materias no previstas, pero necesarias para la consecución de los objetivos comunitarios, en este caso, la interpretación de la necesidad está abierta tanto al orden constitucional interno como al orden constitucional comunitario.

Para un mejor desarrollo de este control sería deseable que la complejidad del actual derecho originario europeo, con más de 1000 artículos repartidos en más de una docena de tratados relevantes, se simplificase con un texto "estatutario" ${ }^{91}$ que recogiese las bases del

89 Como dice HERTEL, Wolfram, Supranationalität als Verfassungsprinzip. Normativität und Legitimation als Elemente des Europäischen Verfassungsrechts, Dunkcer \& Humblot, Berlín, 1998, pág. 85, sólo el ejercicio del poder es originario, no el origen de ese poder: "Lediglich die Herrschaftsübung, nicht dagegen Herrschaftsursprung ist originärn.

90 En este sentido entendemos, por ejemplo, el último párrafo del art. 94 de la Constitución finlandesa de 1 de marzo de 2000, cuando dice expresamente que "las obligaciones internacionales no pueden comprometer los fundamentos democráticos del régimen constitucional».

91 Habida cuenta de la tesis que se mantiene en este trabajo, el término "estatuto" sería más aceptable que el término "constitución", pero seguiremos utilizando este último por ser, hasta ahora, el más empleado por la doctrina. 
orden comunitario y facilitase su comprensión al, tantas veces nombrado, "ciudadano europeo" ${ }^{92}$. Estamos hablando de un texto que recoja unas reglas claras sobre las relaciones entre los órganos de la Unión y de éstos con los Estados miembros y con los ciudadanos ${ }^{93}$.

Evidentemente, no entendemos este texto como la base jurídica de un nuevo "Estado" europeo, sino como la configuración jurídica de la Unión (transnacional) europea. Es decir, la (Ilamémosle) «constitución» europea no puede (ni debe) reemplazar a las constituciones nacionales, sino que como un orden "constitucional» complementario, dependerá de la autoridad y del poder constituyente nacional. No estaríamos de acuerdo con intentos de "constitucionalización" que tengan como objetivo la autolegitimación del sistema comunitario, buscando su independencia del derecho internacional y de los sistemas constitucionales de los EE.MM.94, al menos, en este momento del proceso de integración ${ }^{95}$.

92 Cuando Joschka Fischer, Ministro de Asuntos Exteriores alemán mencionó en su discurso de 12 de enero de 1999 (Bulletin der Bundesregierung $n$. 2/1999, pág. 11) ante el Parlamento Europeo la necesidad de una Constitución europea, el argumento que utilizó fue el de que tal Constitución daría más claridad y orientaría el futuro de Europa. Unos meses más tarde, el 21 de julio, ante el mismo PE, habla de la Constitución como del texto que reúna los valores y principios básicos de la Unión, cuya construcción es concebida como sui generis (Bulletin der Bundesregierung n. ${ }^{\circ}$ 45/1999, pág. 481).

93 SCHWARZE, Jürgen, "Auf dem Wege zu einer europäischen VerfassungWechselwirkungen zwischen europäischen und nationalen Verfassungsrecht», en Deutsches Verwaltungsblatt, Heft 24/1999, págs. 1677-1689, nos recuerda que el debate en torno a una Constitución europea comenzó hace veinte años y resume los temas pendientes antes de elaborar un texto constitucional.

94 Estamos de acuerdo con HARTLEY, Trevor C., Constitutional Problems of the European Union, Hart P., Oxford and Portland, Oregon, 1999, pág. 148: (Community law)... "It may be separate from international law and the law of the Member States, but it is not independent from them"; y con la posición mantenida por elTC alemán en su sentencia de 12 de octubre de 1993 sobre el Tratado de Maastricht (apartado 55) en la que manifiesta que los Estados miembros son los Herren der Verträge.

95 Existen otros puntos de vista como el de BaLAguer Callejón, Francisco, "La constitucionalización de la Unión Europea y la articulación de los ordenamientos europeo y estatal», en Garcla Herrera, Miguel Ángel (dir.), El constitucionalismo en la crisis del Estado social, UPV, Bilbao, 1997, págs. 593-612, especialmente págs. 610-612, quien no encuentra solución a los conflictos jurídicos que actualmente se plantean mientras no exista una Constitución europea, a la cual deban someterse los ordenamientos constitucionales de los EE.MM., es decir, mientras que la Unión no tenga la Kompetenz-Kompetenz. 
Se trataría, en definitiva, de un texto que dejase claro: 1) el respeto a la soberanía de los pueblos europeos, únicos artífices de la construcción europea; 2) el valor de los principios constitucionales como base jurídica de este nuevo desarrollo constitucional; 3) la interdependencia de los ordenamientos comunitario y constitucional; y 4) los mecanismos de mediación para resolver los posibles conflictos entre los diversos intereses en juego.

Interdependencia significa que exista un espacio competencial en el que todos los ordenamientos jurídico-constitucionales de los EE.MM. de la Unión confluyen y esta confluencia tiene consecuencias en el orden constitucional (porque los Estados pierden su autonomía para gestionar las materias comunitarias) y en el orden comunitario (porque la Comunidad es autónoma en la medida en que es constitucional). En definitiva, se trata de articular este espacio común de la mejor manera posible ${ }^{96}$, partiendo de la idea de que la Comunidad no es ajena sino parte (una parte sui generis) del sistema constitucional de sus EE.MM.97. Por eso es tan necesaria la participación activa de los poderes "constituidos" de los Estados miembros y de sus ciudadanos, sin los que no es posible establecer ningún mecanismo de control efectivo ${ }^{98}$.

96 Y para conseguirlo, parafraseando a los profesores LóPEZ PINA, Antonio, y GutiérRez, Ignacio, «Sobre algunos principios de Derecho público para la integración europea", Ponencia presentada en el I Congreso de estudiantes de Derecho Constitucional sobre La reforma constitucional, celebrado en Alicante los dias 14 a 16 de marzo de 2001,: "apostamos por el Estado constitucional como punto de partida...".

97 Uno de los problemas que presenta el estudio de la Comunidad es que es vista como algo "ajeno" a todos sus EE.MM., en este sentido y para el caso danés ver Worren, T., «First No, Then Yes: The Danish Referendums on the Maastricht Treaty 1992 and 1993", Journal of Common Market Studies, 1995, Vol. 33, n. ${ }^{\circ}$ 2, págs. 235-257.

98 Teniendo en cuenta el nivel de participación actual (recordemos que hay quien dice que no existe déficit democrático sino que lo que hay es un déficit de participación), podríamos decir que tenemos una Comunidad mejor que la que nos merecemos, pero mejorable, en cualquier caso. Un ejemplo de esta ausencia de participación es la posición mantenida hasta el momento por elTC español respecto al derecho comunitario. En este sentido ver para una visión general DIEZ PICAZO, Luis María, "El derecho comunitario en la jurisprudencia constitucional española", Revista Española de Derecho Constitucional, n. ${ }^{\circ}$ 54, 1998, págs. 252-272, y para una visión más particularizada, VIRGALA ForURIA, Eduardo, "Tribunal Constitucional, recurso de amparo y Unión Europea", ponencia presentada en Oñate en el congreso celebrado sobre "La protección de los derechos fundamentales en la Unión Europea», los días 14 a 16 de abril de 1999, en vías de publicación. 
Por eso creemos que es el momento de constitucionalizar el derecho comunitario, pero en el sentido constitucional, $y$ no en el comunitario, del término ${ }^{99}$. Porque, en definitiva, los problemas y los avances del derecho comunitario son problemas $y$ avances del derecho constitucional. Si aceptamos que la integración europea es el desarrollo transnacional del derecho constitucional podemos cambiar cualitativamente el debate en torno a la integración. Europa no serían «los otros» sino "nosotros», el déficit (democrático, de participación, de constitución, etc.) no sería un problema de la (ajena) Unión, sino un problema constitucional de cada Estado miembro.

Ahora bien, los problemas son consustanciales a todo proceso de organización del poder, porque como dice el profesor Carlos de Cabo, «no existe continuidad lógica ni histórica entre Derecho y Democracia» ${ }^{100}$ y por eso, porque la relación entre ambos no es ni permanente ni natural, hay que construirla y esta construcción es singularmente necesaria en la Unión Europea.

99 Es muy interesante el artículo de RuBIo LLORENTE, Francisco, "Constitutionalism in the "integrated" States of Europe", Harvard Jean Monnet Working Paper 5/98, que puede encontrarse en la siguiente dirección de Internet: http://www.jeanmonnetprogram.org/papers/98/98-5-.html por la clara exposición de los problemas constitucionales planteados en torno al derecho comunitario, al final del mismo comenta: «However, other considerations apart, the goal of harmonizing national constitutions is likely less quixotic than attempts to provide Europe with a constitution even before it has been formalized as a political unit".

100 Ver DE CABO MARTín, Carlos, "Transformaciones actuales del Estado y del Derecho: perspectivas teóricas», en Garcla HerRera, Miguel Ángel (dir.), El constitucionalismo en la crisis del Estado social, UPV, Bilbao, 1997, págs. 557-573, especialmente pág. 572: "(...) pocas dudas caben acerca de su mutua capacidad legitimadora: la del Derecho democráticamente surgido y controlado y la de la Democracia actuando con arreglo a derecho, en el entendimiento de que ambos se complementan y en concreto, en lo referido a los procesos de transformación social, si bien deben estar amparados en la legalidad, necesitan no sólo la legitimidad sino el impulso y la fuerza de la participación y movilización democráticas». 